\title{
A Educação nos Programas Sociais Brasileiros: pobreza e trabalho
}

\begin{abstract}
Denise De Sordi'
Wenceslau Gonçalves Neto'

'Universidade Federal de Uberlândia (UFU), Uberlândia/MG - Brasil

RESUMO - A Educação nos Programas Sociais Brasileiros: pobreza e trabalho' $^{1}$. Este artigo analisa o papel social da educação como condicionalidade dos programas sociais brasileiros. A abordagem centra-se na elaboração e no desenvolvimento das políticas sociais de transferência condicionada de renda no Brasil e explicita sob quais argumentos morais, políticos e culturais o acesso ao ensino formal foi elevado à centralidade das ações de combate à pobreza. Nota-se que a educação como condicionalidade atua no convencimento acerca de expectativas de mobilidade social entre os sujeitos atendidos pelos programas frente às baixas condições materiais de vida. Desta forma, a educação compõe argumento de legitimação para a transferência de dinheiro, ofuscando tensões e antagonismos entre classes. Palavras-chave: Educação. Programa Bolsa Família. Condicionalidades.
\end{abstract}

ABSTRACT - Education in Brazilian Social Programs: poverty and work. This article approaches the role of formal education as a conditionality to Brazil's social programs. The analysis focuses on developing social cash transfers programs to evidence the moral, political, and cultural foundations that maintain access to formal education as central to eliminate poverty in a long way. In this sense, the role of education as a conditionality serves to manage aspects of convincement about social mobility expectations between the beneficiaries in poverty and unemployment. Therefore, formal education is an argument that validates cash transfer programs to balance tensions and antagonism between opposite classes.

Keywords: Education. Bolsa Família Program. Brazil's Social Programs.

Educação \& Realidade, Porto Alegre, v. 46, n. 3, e106751, 2021.

http://dx.doi.org/10.1590/2175-6236106751 
A Educação nos Programas Sociais Brasileiros

\section{Introdução}

Entre os anos das décadas de 1990 e o ano de $2014^{2}$, os programas sociais de transferência condicionada de renda brasileiros sofreram intensas reformulações e rearranjos institucionais (De Sordi, 2019). No entanto, independentemente de tais reformulações, o acesso ao ensino formal permaneceu como uma das condicionalidades para o ingresso e permanência de famílias de trabalhadores nestes programas.

Analisar a permanência desta condicionalidade faz-se necessário para compreender um processo social que correlacionou educação e trabalho à categoria da pobreza, enquanto questão social a ser gerida pelo Estado, em meio a expectativas por maior empregabilidade e por desenvolvimento social, frente à precarização de empregos, do desemprego e da informalidade.

Considera-se a trajetória da educação enquanto condicionalidade, pelo período dos anos da década de 1990 e início dos anos 2000, de modo a assumir que neste período ocorreu o deslocamento do papel social da educação e do ensino formal, provocado por programas do tipo Bolsa Escola, a nível local, ao longo dos anos de 1990, e a nível nacional com o Bolsa Escola Federal, em 2001, e o Programa Bolsa Família, a partir de 2003 (De Sordi, 2019).

O que se observa é que o acesso ao ensino formal foi apresentado às parcelas empobrecidas da população em conjunto com medidas de caráter socioeducativo, carregadas de sentidos de moralização dos hábitos e condições de vida das famílias atendidas (Gohn, 1997). No início dos anos 2000, com a experiência de nacionalização destes programas, observa-se a aplicação técnica da focalização do público-alvo, e a vinculação à educação é tornada tanto um mecanismo de gestão dos programas (Teles; Stein, 2016) quanto de controle da focalização de modo a legitimar a transferência de renda.

Portanto, nas seções seguintes, este artigo apresenta os debates políticos que inscreveram a educação como condicionalidade dos programas sociais ao longo dos anos de 1990; aborda a tendência à reconfiguração das relações entre educação e trabalho notada nas dinâmicas sociais impostas pelo Programa Bolsa Família (PBF) e analisa concepções em torno do papel da escola e do ensino formal frente aos discursos de combate à pobreza e de desenvolvimento de capital humano.

\section{Concepções em Torno da Pobreza e da Educação para os Programas Sociais}

Nos anos da década de 1990, em um efervescente cenário político e econômico, propostas pela instituição de uma renda mínima ganharam força como possibilidade de minorar os efeitos da intensificação da exploração do trabalho. Foi neste período que a pobreza, como expressão da questão social, pautou o cenário político nacional como uma categoria política (Oliveira, 2007), que foi traduzida pelo Estado em campanhas filantrópicas e em programas socioassistenciais. Estes ti- 
nham por intenção lidar com o processo de empobrecimento dos trabalhadores brasileiros como uma questão social a ser tematizada (Telles, 2013) nos contornos de situações individuais de vida, subordinadas ao aprofundamento das políticas neoliberais no país (Gentili, 1996).

Em diálogo com Behring e Boschetti (2006), é possível afirmar que a Política Social é o campo do conflito entre classes sociais, desenvolvida não necessariamente para diluir antagonismos, mas também para equilibrar concepções entre o Direito Social, as formas de acesso e a execução dos serviços sociais. Assumindo-se que a educação é uma prática mediadora no interior da prática social global (Saviani, 1999), a relação entre o empobrecimento, o trabalho e a educação ocorreu - e ocorre - mediada pela intenção de controle permanente do conflito que pode irromper da abstração de condições vividas frente às relações de produção capitalistas (Leher, 1999).

No caso dos programas sociais vinculados à educação, as formas condicionadas de acesso aos direitos sociais são o ponto de ofuscamento das tensões sociais e têm por objetivo modelar comportamentos individuais a partir da introjeção de hábitos e valores em uma espécie de legitimação da “[...] exclusão como forma de integração" (Gohn, 1997, p. 297). Para o campo da educação, por exemplo, cria-se um consenso social de que o desemprego está relacionado à ausência de ensino formal/qualificação, de modo que é preciso, portanto, ofertar o ensino para que as pessoas possam se empregar, mudar de vida, dentre outros. Este é um processo de autorresponsabilização que considera a desresponsabilização do Estado em relação à “[...] 'questão social”, que só pode ser compreendida em "[...] sua articulação com a autoresponsabilização dos sujeitos carenciados e com a desoneração do capital na intervenção social, no contexto do novo projeto neoliberal" (Montaño, 2010, p. 234-235, grifos no original).

A formação do consenso social em torno de responsabilidades individuais está respaldada nos princípios que organizaram os programas socioassistenciais no país. Em 1995, o BIRD destacava que a “[...] falta de ensino gera pobreza", no sentido de que: “[...] como o trabalho é o principal 'ativo' dos pobres, a melhora na educação [...] seria o mecanismo chave para reduzir a desigualdade" (Correio, 1993 p. 2).

Esta leitura política e social em torno da pobreza promoveu disputas por diferentes formatos de programas socioassistenciais (De Sordi, 2019), que foram, em certa medida, materializados na criação do Programa Bolsa Escola Federal, em 2001. Este programa foi criado a partir de experiências locais de Bolsa Escola, principalmente a que foi implantada no Distrito Federal durante o mandato de governador de Cristovam Buarque. Outras experiências deste tipo ocorreram em diversas localidades, mas esta, em específico, foi o estudo de caso que informou as práticas adotadas pelo Banco Mundial ao abrir sua linha de crédito para este tipo de programa ao Brasil (World Bank, 2002).

No livro A Revolução nas prioridades - da modernidade técnica à modernidade ética, o quarto volume de uma série de estudos de proje- 
A Educação nos Programas Sociais Brasileiros

tos para o desenvolvimento do Brasil, Cristovam Buarque (1994, p. 19) defendeu que:

\begin{abstract}
A procura de uma saída [para a crise social] não se dará apenas por uma melhor distribuição da renda, entre salários e lucros, deixando ao mercado a solução dos problemas. Vai exigir um esforço nacional para a solução dos problemas público globais, através de uma revolução nas prioridades.
\end{abstract}

Após apresentar um diagnóstico do que considerou como os dez erros na formação do tecido social do país, Buarque (1994, p. 131) propôs dez medidas que seriam prioridades de mudança, dentre elas a:

\begin{abstract}
[...] garantia de bolsas oficiais que mantenham na escola mesmo as crianças mais pobres do Brasil. O governo teria que garantir uma renda mínima por família pobre que tivesse filhos na escola. A renda mínima não deve ser por filho, mas sim por conjunto de filhos, nem por todo o ano, mas no mínimo durante o período letivo.
\end{abstract}

Em 2012, ano no qual já se contabilizavam mudanças significativas na conjuntura que havia motivado a escrita do livro citado - no qual os agradecimentos iniciais eram dirigidos, entre outros, a Herbert de Souza, o Betinho $-{ }^{3}$, no livro Bolsa-Escola, história, teoria e utopia, Buarque (2012) agradece, dentre outros, a Fernando Henrique Cardoso pela nacionalização do Bolsa Escola, ocorrida em 2001. Este gesto é significativo das profundas mudanças que ocorreram nas concepções acerca da organização do modelo de implementação das políticas sociais pela via dos programas sociais brasileiros entre os anos das décadas de 1990 e 2000.

Cabe notar que, em 1991, Eduardo Matarazzo Suplicy apresentou projeto de lei que propunha a criação do Programa de Garantia de Renda Mínima (PGRM) ${ }^{4}$. Aprovado por unanimidade no Senado, Fernando Henrique Cardoso o considerou "[...] uma utopia realista" (Suplicy, 2002, p. 124). O projeto não chegou a ser votado pelos deputados, mas desencadeou um debate importante que foi centralizado pela percepção moral de necessidade do acesso ao ensino formal como condição para o recebimento de benefícios. Foi um movimento de oposição à proposta original de Suplicy, que não previa o cumprimento do que hoje conhecemos como condicionalidades ${ }^{5}$.

$\mathrm{O}$ argumento em favor da focalização na família e no acesso à educação, que acabaria por reforçar o modelo do Bolsa Escola frente à opinião pública, foi desenvolvido pelo economista José Márcio Camargo na coluna Opinião Econômica, publicada no jornal Folha de S. Paulo, no final de 1991. Com elogios ao PGRM, Camargo sugeriu à Suplicy que a força de trabalho de crianças pobres teria um valor maior do que a das crianças ricas, devido às características do mercado de trabalho brasileiro, que forçavam o baixo padrão de renda para as famílias de trabalhadores. Para Camargo, a pobreza no país era causada por sua própria capacidade de se autorreproduzir, pela ineficiência do sistema educa- 
cional, pela concentração de terra, pela estrutura fiscal e pela legislação trabalhista, que, em sua avaliação, promoveria contratos de emprego curtos, mal remunerados, e não vincularia o trabalhador às empresas. Com elogios à não promoção pelo Programa de uma burocracia de distribuição de bens e pela possibilidade de rompimento com o ciclo de entrada precoce em empregos aliada à diminuição da evasão escolar - frente ao diagnóstico feito -, Camargo encaminhou duas sugestões para o Programa.

A primeira, era de que o Programa deveria centrar-se nas crianças, e não nos mais velhos, como havia sugerido Suplicy. A segunda, era de que por, em sua visão, o Programa estimular a informalidade, ele deveria ser restrito aos trabalhadores com carteira assinada, ou criar um outro programa que complementaria a renda de todos os trabalhadores, com a condição de que os seus filhos estivessem em escola pública. Neste ponto, Camargo foi enfático ao finalizar a coluna com o alerta de que a complementação deveria ser para todos os filhos, e não para cada filho.

Foi pautada por este debate a característica que permaneceu em todos os programas de transferência de renda condicionada desde então. O foco nas famílias de trabalhadores empobrecidos e no acesso à educação foi instituído como a melhor abordagem e encontrou eco nas sugestões e experiências de organismos internacionais.

Com elogios e críticas, e em meio a todas as mobilizações sociais que agitavam os cenários político e social dos anos de 1990, e em consonância com a pressão das campanhas pelo combate à fome (Bava, 1998), o debate em torno da proposta encaminhou a aplicação de sua ideia como uma ampliação de redes de proteção já existentes por governos locais, incentivando a expansão dos programas locais de Bolsa Escola. A proposta estava no campo das possibilidades políticas à época quando, segundo Rocha (2013, p. 23), apenas $88 \%$ das crianças em idade escolar obrigatória frequentavam as escolas na área urbana, e $78 \%$ na área rural.

Para Buarque, os programas Renda Mínima e Bolsa Escola estavam vinculados em seu nascimento, porém, haviam se desenvolvido com base em uma lógica completamente diferente. Durante a Conferência Internacional sobre a Renda Mínima: Discussões e Experiências, realizada em Brasília, em 1998, Buarque exemplificou a diferença entre o Renda Mínima e o Bolsa Escola. Para ele, o Renda Mínima “[...] parte do problema de que a pobreza é falta de renda e ao garantir a renda mínima as pessoas sairão paulatinamente da pobreza”, e o Bolsa Escola conserva "[...] a lógica de que as pessoas são pobres porque não têm educação e não têm educação porque não têm renda e as crianças têm que trabalhar".

A lógica do programa, descrita por Buarque como algo simples, é de que se paga para as crianças estudarem de modo a complementar não a renda, mas a educação. Para essa lógica funcionar, o Bolsa Escola foi implantado em Brasília com a condição de que "[...] todas as crianças 
A Educação nos Programas Sociais Brasileiros

em idade escolar estejam matriculadas e nenhuma delas falte mais do que duas aulas naquele mês. Se dos três filhos apenas dois tiverem [sic] matriculados não entra na Bolsa-Escola”. Para Buarque, esta condição seria o ponto diferencial entre o Bolsa Escola e os programas tidos por ele como assistencialistas. Por esta via, com essa regra, Buarque afirmou que o governo estava "[...] usando a lógica do mercado" (Senado Federal, 1998).

Cabe ressaltar que a condicionalidade da educação passou por transformações. Se no argumento que a originou, o acesso à escola realmente se constituía um problema, quando o Bolsa Escola Federal foi implantado, em 2001, já não era mais uma questão urgente. Como registrado por Rocha (2013, p. 62), 96\% das crianças na faixa etária alvo frequentavam a escola. Isto, ressalta-se, a despeito da qualidade com que esse dado era atingido.

Em 2001, o objetivo do Bolsa Escola Federal, foi declarado pelo então ministro da educação, Paulo Renato Souza, como um projeto de incentivo financeiro para que a família colocasse e mantivesse "[...] a criança na escola. Queremos que todos concluam o ensino fundamental”. De acordo com o ministro, “[...] a educação fará a 'revolução social' no país” (Correio, 2001, p. A-2).

De acordo com Valente (2003, p. 172), uma das coordenadoras do Bolsa Escola Federal, o programa "[...] reiterou a universalização do ensino fundamental, definida na gestão do ministro Paulo Renato de Souza”. Tal programa, sob a gestão do Ministério da Educação, se baseou em aspectos específicos da condição de pobreza, ao associar o acesso à educação à melhoria das condições de vida. A categoria pobreza e o acesso ao ensino formal haviam sido articulados enquanto resposta institucional a ser ofertada pela via dos programas sociais.

Quando criado, o Bolsa Escola Federal baseou-se em uma “[...] concepção educativa que afirma a importância do trabalho para a formação humana", de modo a "[...] considerar que se garanta, no âmbito da educação escolar, que todos tenham acesso ao conhecimento" o que, ainda de acordo com Valente (2003, p. 172) "[...] não implica mera reação à crença no trabalho como salvação para o pobre/infrator”, pois isso representaria, na perspectiva dos coordenadores do programa, "[...] a negação do valor conferido ao trabalho por segmentos socioculturais desfavorecidos. Negaria também que o lócus do processo educativo dáse em todas as dimensões da vida".

Em outros termos, a implementação do Programa Bolsa Escola Federal tratava da gestão da vida de parcela da população identificada como pobre de forma desvinculada dos princípios constitucionais e isolada da Lei Orgânica de Assistência Social (LOAS) (Justo, 2007; Draibe, 2003), o que permitiu que a pobreza permanecesse como um campo aberto de disputa e de gestão política. A expressividade deste programa pode ser notada quando, em 2002, registrou-se a adesão de “[...] 5.545 dos municípios brasileiro [sic] (99\% deles) e com quase nove milhões de crianças cadastradas" (Valente, 2003, p. 167). 
A gestão do então ministro Paulo Renato de Souza estava em consonância com o projeto de Reforma do Estado levado a cabo pelo $\mathrm{MARE}^{6}$, sendo, no campo do debate sobre a universalização da educação, as tensões em torno da formulação e da aprovação da Lei de Diretrizes e Bases da Educação, de 1996, uma das maiores expressões das disputas então travadas e que foram determinantes para a atual configuração do ensino formal (Cestari, 1997).

Com a mudança no cenário político nacional e o lançamento do programa Fome Zero em 2003, abriu-se mão do componente educacional, universalizando a renda ao universo de famílias consideradas pobres. Isto significou o rompimento com a ideia das condicionalidades, contida no Bolsa Escola Federal, e, pode-se dizer, foi um dos motivos pelos quais o Fome Zero teve curta existência como política central para a área social do governo petista (De Sordi, 2019, p. 116).

Em substituição ao Fome Zero, o $\mathrm{PBF}^{7}$ introduziu novamente a condicionalidade sob a vigilância ativa da rede de assistência social. A questão, segundo Rocha (2013, p. 89, grifos nossos), era de que com a tentativa de universalização da distribuição de benefícios no Fome Zero, o governo havia:

[...] perdido um álibi precioso: o de que o pagamento do benefício em dinheiro era o meio de fazer com que as famílias pobres enviassem suas crianças à escola e respeitassem o calendário de assistência médica básica. Esse álibi tinha sido sempre usado para esgrimir a oposição de um amplo continente da sociedade brasileira que se opunha - e ainda se opõe - às transferências de renda focalizadas. Segundo os opositores das transferências, o dinheiro repassado às famílias pobres seria desperdiçado com gastos impróprios, incentivando a preguiça e desestimulando o trabalho.

Em diálogo com Rocha, ressalta-se que o processo de entrelaçamento das condicionalidades aos programas sociais permitiu significar processos estruturais como questões sociais individualizadas e ligadas ao signo da pobreza. Este foi um movimento que permitiu a legitimação social de programas de distribuição condicionada de renda articulados ao ensino formal, em um processo que habilitou o acesso condicionado ao Direito Social da educação.

O papel social da educação, direcionado à funcionalidade de legitimação dos programas sociais, pressupõe práticas e valores que devem ser incorporados pelos sujeitos, de modo que é possível considerar que "O educando, por sua vez, é direcionado para determinados padrões comportamentais por meio de instituições como a escola, a universidade e o trabalho, de modo a adequar-se às demandas de uma nova ordem subjacente” (Vicente; Gonçalves Neto, 2018, p. 434). 


\title{
A Condicionalidade da Educação no Combate à Pobreza
}

A aparente naturalização da efetividade da educação no combate à pobreza está intrinsecamente relacionada às concepções mobilizadas para identificar o público a ser atendido. A categoria da pobreza e suas definições implica identificar os sujeitos pobres e é também uma maneira de abstração de condições de vida que são inteiramente relacionais. A avaliação das condições materiais das famílias foi uma prática que perdurou nos programas locais e nacionais, que seguiram com a instrumentalização do serviço social em vigilância socioassistencial enquanto instrumento "[...] de controle e intervenção na vida cotidiana da população” (Montaño, 2010, p. 231).

Há aqui um componente crítico relacionado às formas de percepção sobre os costumes e hábitos de consumo que caracterizariam as condições de vida de uma 'pessoa pobre'. Apesar do apelo técnico e 'eficiente', as formas de avaliação dos programas sociais, são, em geral, definidas mais por impressões ligadas ao consumo do que por critérios técnicos de fato. Um breve caso sobre o Bolsa Escola, relatado por Buarque, pode ilustrar essas formas de percepção:

\begin{abstract}
A cada ano eu fazia uma avaliacão das famílias e eliminava aquelas que melhoravam de vida. Percebemos que o critério de considerar melhora de vida não é suficiente para garantir a criança na escola. Existem casos até anedóticos, se não fossem dramáticos e trágicos, como o de uma família que perdeu a Bolsa-Escola porque a fiscal descobriu que ela tinha um telefone na casa. Depois, descobriuse que o telefone era um enfeite que a patroa havia dado para a mãe da criança e esta o botou em cima da mesa. Resolvemos isso adiando para cada dois anos pelo menos a avaliac,ão porque fiquei preocupado com as crianças que perdiam a Bolsa-Escola (Senado Federal, 2004).
\end{abstract}

Com a criação do Bolsa Escola Federal e a incorporação da educação enquanto uma dentre outras condicionalidades no PBF, esse tipo de vigilância socioassistencial foi, em certa medida, transferido para a rede institucionalizada pelo SUAS e pelos $\mathrm{CRAS}^{8}$, e os sujeitos atendidos passaram a lidar com o jogo destas percepções nestes espaços a partir do que Marins (2014, p. 557) chama de repertórios morais e estratégias individuais, que constroem o

[...] papel social de 'candidato', desenvolvendo discursos, comportamentos e linguagens próprias a uma situação de entrevista. Esta entrevista não é uma entrevista qualquer; ela tem como objetivo analisar o perfil do cliente (sofrimento, quantidade de filhos etc.), para julgar se a pessoa será legitimada como 'pobre' merecedor de uma bolsa.

As condicionalidades são interpretadas pelos sujeitos como as regras a serem cumpridas para o acesso ao benefício. Estes repertórios morais e estratégias individuais têm influência direta sobre os objetivos, resultados e narrativas em torno da condicionalidade da educação. 
Se expressam na organização das expectativas postas para os sujeitos atendidos e podem ser evidenciados a partir de sua organização formal na Agenda da Família, distribuída aos beneficiários do PBF, pelo Ministério do Desenvolvimento Social (MDS), a partir de $2010^{9}$.

Entre os assuntos abordados na Agenda, vale notar o tópico: Quais são as oportunidades para melhorar as condições de vida da sua família?, que apresenta um personagem segurando um cartão azul - que remete à carteira de trabalho brasileira - e um caderno - em clara alusão à educação. No contexto de utilização da imagem, ainda que o programa ofereça como benefício imediato a transferência condicionada de dinheiro, está presente a associação direta entre a melhoria das condições de vida das famílias ao emprego e ao ensino formal.

No tópico da Agenda sobre oportunidades para melhorar as condições de vida, é informado que o "[...] Programa Bolsa Família procura promover outras ações com o objetivo de melhorar a qualidade de vida das famílias beneficiárias":

Muitas entidades da sua comunidade e dos governos do seu município e do seu estado oferecem ações voltadas para o aumento da escolaridade, qualificação profissional, geração de trabalho e renda e melhoria das condições de moradia. Informe-se sobre programas e ações desenvolvidos na sua cidade e participe sempre que puder (Brasil, 2010, p. 28).

Neste tópico, há um entendimento a partir do qual o PBF instrui as ações e os caminhos que os sujeitos devem seguir para atingir o status de trabalhador qualificado com o aumento da escolaridade a qualificação profissional (Brasil, 2010, p. 28). Sendo estas as responsabilidades (contrapartidas) que estão colocadas implicitamente como atitudes esperadas dos beneficiários. Duas questões que se inter-relacionam estão colocadas. A primeira, refere-se ao pressuposto de que o emprego seria um fator instantâneo de melhoria de vida, desconsiderando questões como baixos salários, contratos temporários e/ou precários, dentre tantas outras condições de trabalho possíveis. Isso implica ainda que a educação formal, realizada através da frequência escolar, ou a habilitação para outras funções, realizada através de cursos oferecidos agregaria capital humano que se traduziria em qualificação profissional e, portanto, no aumento de oportunidades.

A segunda questão, refere-se ao fato de que, de acordo com pesquisas quantitativas realizadas a partir de análises do CadÚnico ${ }^{10}$, a maioria dos beneficiários do PBF é de trabalhadores inseridos em empregos com alta rotatividade, baixa remuneração e muitas vezes, mas não como regra, informais (Barbosa; Corseuil, 2013).

Arroyo (2010, p. 1398) argumenta que as políticas sociais são reguladas pelo conceito de redução das desigualdades sociais, o que, por sua vez, ignora as relações constituídas entre os eixos das políticas e seu movimento social, edificando valores em torno da educação e do emprego: 
A Educação nos Programas Sociais Brasileiros

[...] 'estude e terás emprego', 'tire o diploma de ensino fundamental, médio e terás trabalho'. O acesso ao trabalho como redutor das desigualdades. A inserção social pela educação tem como mediação a inserção no trabalho. Quando essa mediação do trabalho entra em crise, as desigualdades se aprofundam, e as políticas educativas perdem significado [...]. A articulação tão mecânica nas políticas de acesso e permanência, ou de currículos por competências, tendo como mediação o acesso ao trabalho, expõe essas políticas e sua relação com a diminuição das desigualdades ao enfraquecimento até ao fracasso, sempre que o trabalho entra em crise".

Na linha do que foi apontado por Arroyo, e subjacente à tentativa de articulação do PBF com oportunidades, está a relação com o entendimento de que a partir do momento em que todos fossem qualificados seriam incorporados pelo mercado de trabalho. O economista Paul Singer (2001, p. 119-120) frisa, por exemplo, que isso não seria suficiente para promover a absorção dos trabalhadores: "[...] se todos os trabalhadores desempregados incrementassem seu nível de qualificação, o único resultado seria uma concorrência mais intensa entre eles, com provável queda dos salários pagos"11.

De acordo com Teles e Stein (2016 p. 197), esta é uma visão que legitima

A educação como redenção - e como condicionalidade [e que] segue a lógica da concepção da Organização das Nações Unidas para a Educação, a Ciência e a Cultura (Unesco), na qual é entendida como um caminho para se conseguir um desenvolvimento humano com menos pobreza, exclusão aos direitos, discriminação, opressão. A concepção de educação, a partir do desenvolvimento pleno do ser humano, não ultrapassa a tentativa de coesão social, de adaptação ao sistema marcado por competitividade no mundo do trabalho e de aprendizado de conteúdos escolares.

A aproximação entre o combate à pobreza e o papel social das escolas redesenha os contornos que significam o trabalho para a parcela da população considerada pobre, transferindo parte importante da responsabilidade por questões que são sociais, isto é, coletivas e da esfera da produção, no espaço das relações de reprodução.

Com o PBF, a educação foi cristalizada como instrumento de combate à pobreza no longo prazo, consolidando o pressuposto de seu papel de equalizadora das desigualdades sociais. Estas mudanças deslegitimaram a concepção de que o papel da educação "[...] diz respeito a prover as condições subjetivas do processo de transformação que, entretanto, só podem ter eficácia em articulação com as condições objetivas" (Bassani, 2009, p. 111).

Como significantes do desmonte das possibilidades de universalização das políticas sociais e do direito à educação como emancipação, 
condições imediatas de alívio foram socialmente aceitas e legitimadas enquanto instrumento de promoção do desenvolvimento social.

O contexto histórico que promoveu as políticas de transferência de renda como a melhor das possibilidades compôs, em um cenário macro, a distinção do programa neoliberal que, no Brasil "[...] marca um período único na moderna história brasileira”, pois é "[...] a política antirreformas sociais, antirregulacionista, antidireitos do trabalho e direitos sociais em geral que marca o neoliberalismo" (Oliveira, 2018, p. 66), e mediante a este processo coadunou a necessidade de universalização do ensino formal ao aprofundamento das políticas neoliberais.

A vinculação do acesso ao ensino formal enquanto condicionalidade de programas sociais amplia e altera não só o papel social da educação, mas o repertório de atuação das escolas (Kawauchi, 2019). Há, em certa medida, um deslocamento das práticas pedagógicas criativas e libertadoras, inerentes ao processo de formação para a cidadania, para as funções de fiscalização e de gestão de parcelas da população empobrecida que passam a acessar o ensino formal por meio das condicionalidades.

Cabe pontuar que a imagem e a narrativa dos programas sociais compõem um campo de conflitos em aberto, no qual há a tentativa de persistência de visões sobre determinados papéis de desenvolvimento econômico e social que deveriam ser atribuídos aos sujeitos atendidos pelos programas sociais. A interpretação de Buarque (2012, p. 42-43, grifos nossos) em torno do PBF, a despeito da disputa política travada em favor do Bolsa Escola ${ }^{12}$, permite compreender o tipo de interpretação que se busca imprimir aos sujeitos atendidos:

\begin{abstract}
A mudança no Brasil do nome 'Bolsa-Escola' para 'Bolsa Família' trouxe por isso um retrocesso no nível de consciência das mães, que antes pensavam 'recebo esta bolsa porque meus filhos vão à escola e pela escola sairão da pobreza' e agora pensam 'recebo essa renda porque minha família é pobre e se sairmos da pobreza perderemos a bolsa.' [...]. Também foi um retrocesso o fato de passar a pagar por criança e não por mãe.
\end{abstract}

As formas de organização das dimensões de reprodução (Bhattacharya, 2019) significativas de processos de exploração e expropriação foram matizadas por programas assistenciais que interpuseram condicionalidades para a gestão da vida social, separando, ao unir essas duas esferas. Como pontua Mauriel (2008, p. 332):

O diagnóstico da pobreza ao desvincular a pobreza de seus determinantes estruturais, desvincula os indivíduos pobres de seus lugares no sistema produtivo. A essência, passa, então, a constituir um atributo individual orientada por critérios éticos e morais.

Para Petitat (1994, p. 7), “[...] a escola contribui para a produção social". De acordo com o autor, não se trata de abordar “[...] única e [ou] fatalmente [a] reprodução social”, nesse sentido, é preciso “[...] tentar unir 
A Educação nos Programas Sociais Brasileiros

produção da escola e produção da sociedade de amanhã”. Se se considera que a escola tem por função produzir certo sentimento de coesão social (Petitat, 1994), a educação formal, exerce papéis cambiantes que evidenciam as disputas em torno de seu papel no interior do contexto educacional e das possibilidades de ampliação democrática. Como pontuam Vicente e Gonçalves Neto (2018, p. 467-438):

\begin{abstract}
Destinada à transmissão da cultura de uma geração para a outra, a educação atua no sentido de permitir que o patrimônio simbólico que dá sentido aos modos de vida se perpetue ao longo do tempo, submetido a adaptações decorrentes das conjunturas de cada época. A educação também produz cultura, na medida em que ressignifica as culturas existentes. Exatamente por ser um meio, e não um fim em si mesmo, adquire caráter polissêmico, cambiante conforme o ponto de vista do agente que a considera.
\end{abstract}

O projeto de minorar, e não de transformar condições estruturais, pode ser localizado no campo da educação enquanto condicionalidade dos programas sociais. Enquanto práticas políticas, portanto, sua análise deve considerar:

[...] não apenas a dinâmica do movimento do capital, seus meandros e articulações, mas os antagônicos e complexos processos sociais que com eles se confrontam [...] as políticas educacionais, mesmo sob semblante muitas vezes humanitário e benfeitor, expressam sempre as contradições supra-referidas (Shiroma, 2004, p. 9).

\title{
O Papel da Educação nos Programas Sociais
}

De acordo com Hillesheim e Garcia (2019, p. 480), a relação entre educação e trabalho é um "[...] binômio sempre presente nas proposições que vislumbram a política de educação como mediação essencial para o enfrentamento da pobreza e da desigualdade social no Brasil”. A partir da análise de planos nacionais da educação e outros documentos normativos, os autores consideram que “[...] o direito à educação pública está sempre condicionado aos interesses do mercado de trabalho, caracterizado por relações cada vez mais flexíveis e precarizadas”. Para Teles e Stein (2016 p. 206), “[...] o debate moral, desencadeado pelo discurso neoliberal, colocou sobre os indivíduos a responsabilidade exclusiva pelos resultados de suas vidas".

Arroyo (2010, p. 1398) argumenta que as políticas sociais são reguladas pelo conceito de redução das desigualdades sociais de modo que pautam determinada "[...] repolitização conservadora da sociedade", o que por sua vez ignora as relações constituídas entre os eixos das políticas e seu movimento social, edificando valores em torno da educação e do emprego, de modo que "[...] a inserção social pela educação tem como mediação a inserção no trabalho”, gerando um 
efeito de esvaziamento da política, mediante o qual "[...] as políticas educativas perdem significado".

Enquanto condicionalidade, os objetivos postos para a educação estão alinhados à ideia de correção de uma vulnerabilidade ${ }^{13}$ social, que é tratada no âmbito do indivíduo, e que deve ser atendida por ações compensatórias do Estado (De Sordi, 2019).

Como pontua Cidamamore (2007, p. 21-22), o Estado que é responsável pelas "[...] condições que levam tanto à produção de pobreza como a sua eliminação", ao não explicitar os motivos que levam expressiva parcela da população à pobreza, permite aos seus diversos segmentos "[...] culpar os pobres por suas pobrezas". Esse processo de culpabilização, de forma recorrente, se expressa na argumentação de que é preciso incutir valores nos sujeitos atendidos através da educação (Gentili, 2011, p. 228).

Considerando que a educação é um “[...] fenômeno condicionado, determinado pela estrutura da sociedade e submetido ao controle político das forças dominantes" (Bassani, 2009, p. 110), a articulação entre o acesso à educação e a renda ocorre pelo viés de concepções sobre a educação que estão subordinadas ao desenvolvimento econômico, de forma condicionada ao argumento de mobilidade social através da aquisição de maior qualificação pelos trabalhadores.

Deste modo, o ensino passa a ser instrumentalizado "[...] em meio de treinamento de força de trabalho sem ônus para o capital” (Montaño, 2010, p. 231). No mesmo sentido, argumentam Hillesheim e Garcia (2019, p. 480), ao pontuarem que:

$$
\begin{aligned}
& \text { [...] o direito à educação pública está sempre condicionado } \\
& \text { aos interesses do mercado de trabalho, caracterizado por } \\
& \text { relações cada vez mais flexíveis e precarizadas. [...] o dire- } \\
& \text { cionamento da política pública de educação [...] responde } \\
& \text { a necessidades objetivas e subjetivas da reprodução da } \\
& \text { força de trabalho de acordo com as exigências do desen- } \\
& \text { volvimento do próprio modo de produção regido pelo ca- } \\
& \text { pital. }
\end{aligned}
$$

No contexto brasileiro, o desenvolvimento dos programas socioassistenciais e as sucessivas reformas às quais foram submetidos, ocorreram em um cenário mediante o qual era preciso atenuar as críticas ao programa de ajuste econômico. Para tanto, o Banco Mundial abriu uma linha de "[...] financiamento de programas sociais compensatórios voltados para as camadas mais pobres da população, destinados a atenuar as tensões sociais geradas pelo ajuste" (Soares, 1996, p. 27).

Assim, os programas sociais brasileiros, amalgamados no PBF, expressaram a tendência econômica engenhosa que promoveu o encontro entre o desenvolvimento econômico e o individualismo, direcionando o foco das políticas sociais para o desenvolvimento de capital humano. Tal enfoque, que se tornou característico dos programas sociais, se deu, conforme registrado por Mauriel (2008, p. 28), quando: 
A Educação nos Programas Sociais Brasileiros

[...] o sentido das políticas sociais foi reconduzido na direção do alívio da pobreza, na tentativa de responder aos processos de precarização generalizada de vida da maioria da população mundial que depende da venda de sua força de trabalho, sem, no entanto, mexer na dinâmica contemporânea de acumulação de riqueza.

O alívio da pobreza tornou-se gradualmente admissível na atuação de organismos multilaterais a partir da década de 1960, pois se configurou não pela existência da pobreza em si, mas "[...] como um instrumento de crescimento econômico", esse preceito solapou o "[...] paradigma econômico que priorizava o crescimento econômico e direcionou crescentes atenções para a redução direta da pobreza" (Mauriel, 2008, p. 139-140). De modo que os programas sociais foram tensionados entre sistemas compensatórios/focalizados e de universalização mediante as reformas macroeconômicas ocorridas ao longo da década de 1990.

O formato escolhido para os programas sociais impulsionou as contraditórias condições que estão colocadas ao ensino formal como espaço de emancipação e, ao mesmo tempo, de formação para o emprego e/ou de atendimento às necessidades básicas. $\mathrm{O}$ marcador da condicionalidade educacional do PBF - que é a exigência da frequência escolar - indica o deslocamento das possibilidades de desenvolvimento e controle sociais (Behring; Boschetti, 2006) a partir de concepções de instrumentos para a transformação estrutural, para a aplicação do instrumental da fiscalização que prioriza "[...] a teoria do investimento em capital humano" que, por sua vez, "[...] ganha importância como meio [...], colocando que esta não é fenômeno estrutural, resultante do modo de produção capitalista, mas como algo conjuntural de responsabilidade individual" (Teles; Stein, 2016 p. 198).

Por ser configurado como condicionalidade, o papel conferido à educação e ao acesso ao ensino formal foi matizado pela vigilância e pela racionalidade técnica que gerem os programas de transferência condicionada de renda que têm por objetivo "[...] modelar o comportamento social e as relações sociais" (Mauriel, 2008, p. 23). De fato, somente o registro da frequência escolar para a formação de bases informacionais (Sen, 2010) do PBF tem sido indicado por pesquisadores como pouco eficiente para se medir fatores como qualidade de acesso ao ensino e a integração entre os agentes que participam do processo educativo (Teles; Stein, 2016 Silva, 2014).

Kawauchi (2019) observa que um dos efeitos do registro de frequência ser a forma pela qual o programa social é percebido nas escolas gera a não percepção dos educadores em relação ao completo funcionamento do programa, reforçando estereótipos que compõem o constructo social fundado nas percepções sobre a figura do pobre e da pobreza (Telles, 2013; Marins, 2014; De Sordi, 2019).

Tanto o Bolsa Escola (1995) quanto o Bolsa Escola Federal (2001) e o PBF (2003) apresentaram a educação como via naturalizada para a mobilidade social a partir de atitudes individuais. Todavia, nota-se 
que a condicionalidade educacional cumpriu, no período de desenvolvimento e execução destes programas, os requisitos para que estes se tornassem socialmente aceitáveis, na medida em que ofuscou antagonismos presentes em torno de questões como manutenção de baixos salários, manutenção de privilégios sociais bem como a manutenção de lugares sociais à parcela de trabalhadores empobrecidos.

Silva, Yazbek e Giovani (2014, p. 220) registram como avaliação do sistema educacional que, visto pela ótica dos programas de transferência condicionada de renda mínima, além de se considerar que o rompimento do ciclo intergeracional da pobreza deve estar centrado em melhores condições de acesso à educação, é preciso “[...] considerar que a causa estrutural da pobreza no Brasil é a desigualdade na distribuição da renda e da riqueza socialmente produzida mais do que a incapacidade de geração de renda”.

De acordo com Petitat (1994), o interesse em torno do crescimento econômico em relação estreita com o planejamento de fundos educacionais não é novo, porém, se configura a partir da década de 1960 com o embasamento em teorias econômico-sociais. Este foi um debate levado a cabo pelos economistas da Faculdade de Ciências Econômicas da Universidade de Chicago, com a argumentação, resumida por Petitat (1994, p. 217), de que:

[...] a educação não é um consumo, mas um investimento que traz dividendos aos indivíduos (maior número de opções, salários mais elevados) e às coletividades (fator de crescimento econômico). Um investimento insuficiente neste setor pode representar um entrave ao crescimento.

Petitat (1994, p. 217) observa que o "[...] o trabalhador assalariado não possui em seus conhecimentos um capital possível de frutificar por si mesmo e para si mesmo", portanto, a teoria de desenvolvimento do capital humano, amplamente utilizada em programas compensatórios que envolvem a educação, desconsidera que "[...] o conhecimento profissional somente se torna capital através do empregador, para quem o assalariado é um fator de produção dentre outros”. Deste modo

\begin{abstract}
[...] a linguagem utilizada pelos detentores do 'capital humano' dá a ilusão de que o assalariado é um capitalista que investe em si próprio. Ora, sua posição é antes a de um consumidor que pode fazer certo cálculo econômico: na sua decisão de prosseguir ou de abandonar os estudos, o aluno pode fazer intervir, dentre outros elementos, uma estimativa das vantagens salariais para um ou diversos anos de estudos suplementares. O aluno não investe: ele adquire mercadorias (tecnologias e conhecimentos) que conta poder revender mais tarde a quem deles tenha necessidade como capital (Petitat, 1994, p. 217).
\end{abstract}

Estas leituras sociais e seus contrapontos, fortemente embasados em postulados neoliberais (Mauriel, 2008), foram aplicadas no contexto brasileiro pela via dos programas sociais. O efeito foi o rebaixamento 
A Educação nos Programas Sociais Brasileiros

nas possibilidades de ampliação da cidadania, que passa a ser promovida enquanto qualidade individual de ação, em um processo de aparente esvaziamento do território político dos conflitos sociais que modelam as Políticas Sociais (Gohn,2014; Telles, 2013; Behring, Boschetti, 2006).

A condicionalidade da educação cumpre o papel de remodelar o repertório que informa as possibilidades de desenvolvimento social que poderiam ser impulsionadas por diferentes experiências educacionais. Cumpre, ainda, importante papel na focalização da distribuição de dinheiro aos sujeitos empobrecidos. De acordo com Teles e Stein (2016, p. 196), a focalização é estratégia: “[...] visa a redução do gasto social [...] ao gosto do ajuste estrutural dos organismos internacionais, que colabora para a interrupção da luta pela universalização dos direitos sociais e desestruturação das políticas universais no Brasil”.

De acordo com Lima, Aranda e Lima (2012, p. 55), a “[...] naturalização das medidas externas dos organismos multilaterais tem sido trabalhada como receita às necessidades locais do Estado brasileiro, uma vez que educação e políticas sociais assistencialistas são colocadas no mesmo patamar de equivalência", com o sentido explícito de medidas corretivas para as quais não há responsabilização do Estado ou do mercado.

Este debate aponta para "[...] consequências que não podem ser negligenciadas acerca das políticas escolares” (Petitat, 1994, p. 217). Teorias que pareciam arrefecidas nos anos da década de 1970 foram retomadas no direcionamento do desenvolvimento das políticas educacionais, no contexto brasileiro, nos anos de 1990. É desse sentido que decorre a associação naturalizada entre educação e combate à pobreza como solução para o desenvolvimento econômico e social no contexto dos programas de transferência condicionada de renda brasileiros.

\section{Considerações Finais}

Trabalho e educação, no cenário dos programas sociais de transferência condicionada de renda, apresentam-se transmutados de suas possibilidades de emancipação humana - e de um valor significativo de dignidade para os sujeitos - para o controle das possibilidades sociais em prol de objetivos localizados na dimensão do desenvolvimento econômico.

Pesquisas qualitativas têm apontado que o desemprego é um dos maiores fatores de instabilidade para os beneficiários do PBF como registrado por Serapião $(2018$, p. 99) a partir de entrevistas: “[...] todas as famílias possuíam pelo menos um membro procurando ativamente trabalho", uma das críticas frequentes do público atendido é de que o programa "[...] não ajuda a acessar trabalho". Uma das pessoas entrevistadas chegou a afirmar: “'[...] deveria dar mais trabalho, ao invés de dar 100 reais; pois trabalho dá autoestima e conhecimento'” (Serapião, 2018, p. 125). Uma carta enviada ao presidente Lula e transcrita por Cohn (Cohn, 2012, p. 61) registrava: 
Senhor presidente uma ajuda ela se acaba; o que necessito é de um emprego que garanta minha vida, sem que eu possa estender a mão e pedir uma esmola. Me ajude; falo com o sentimento de minha alma, dei-me um emprego para lavar chão, mas que eu trabalhe com dignidade.

Uma beneficiária do PBF, entrevistada por Pinzani e Rego (2014, p. 141), afirmou: "Olha, o que nós queremos, a mudança, é de uma vida melhor, eu queria mesmo ganhar é a suado meu salário, que tivesse que trabalhar, toda mãe quer isso para seus filhos, sua família, sua casa". Nota-se, por fim, que a educação como condicionalidade dos programas sociais brasileiros, na prática, tende a organizar moralmente a gestão da vida de parcelas empobrecidas da população. Ao ser abstraída das condições materiais vividas, desconsidera a complexidade de fatores estruturais que intermediam as relações das famílias atendidas e a forma como acessam a totalidade dos Direitos Sociais.

No plano da gestão dos próprios programas, a condicionalidade da educação modela as formas de controle e avaliação dos objetivos a serem atendidos, no escopo das políticas de ajuste econômico que organizam os parâmetros e limites para o desenvolvimento social. A educação e o ensino formal passam ao papel de instrumentos de medição de eficiência de gestão e de projeção de expectativas por determinada mobilidade social. As baixas condições materiais que se interligam às relações produtivas capitalistas são ofuscadas pelas concepções que alinham a pobreza, a educação e o trabalho.

Recebido em 23 de agosto de 2020 Aprovado em 06 de maio de 2021

\section{Notas}

1 Este artigo apresenta os resultados da pesquisa Trabalho e Ensino Formal: $O$ papel da educação na dimensão dos programas de distribuição condicionada de renda, desenvolvida no âmbito do PPGE/UNIUBE em estágio pós-doutoral, sob a supervisão do Prof. Dr. Wenceslau Gonçalves Neto.

2 Considera- o período entre 1990 e 2014, pois é durante estes anos que os Direitos Sociais previstos na Constituição Federal de 1988 passam a ser implementados a partir do desenvolvimento de uma rede de Políticas Sociais. Nos anos 2000, os programas sociais tornam-se robustos como a maneira exemplar de implementação e de acesso às Políticas Sociais, e consolidam-se ao serem expandidos, pelo menos até 2014. A partir deste ano, o cenário político nacional começa a mudar, e com ele, as bases de gestão, implementação e controle social dos programas sociais.

3 Betinho sobressaiu-se ao longo dos anos de 1990 como o articulador da Campanha da Ação da Cidadania contra a Fome, a Miséria e pela Vida da qual emergiu uma das primeiras ações do Estado, no período posterior à redemocratização do país, centrada na ideia de combate à fome e à pobreza. A Campanha reuniu diferentes propostas para o país e impulsionou a criação do Conselho Nacional de Segurança Alimentar e Nutricional (CONSEA) por Itamar Franco, em 1993. De existência curta em seus moldes originais, o CONSEA foi desativado em 1995 por Cardoso, e substituído pelo Programa Comunidade Solidária (PCS) que 
A Educação nos Programas Sociais Brasileiros

tinha como uma de suas características mais marcantes trabalhos voluntários direcionados às ações educativas em regiões consideradas pobres.

$4 \mathrm{O}$ projeto era resultado do acúmulo de debates no interior do Partido dos Trabalhadores (PT), desde a década de 1980 (Suplicy, 2002, p. 122). Nota-se que a proposta de uma renda mínimajá vinha sendo defendida no Brasil, pioneiramente, nos anos de 1970 pelo economista Antônio Maria da Silveira, que auxiliou Suplicy a articular politicamente o projeto em 1990.

5 De acordo com Suplicy (2002, p. 93-94), sem as condicionalidades não haveria "[...] qualquer estigma, sentimento de vergonha ou humilhação em receber um benefício que é concedido a todos por uma questão de cidadania", se constituiria desse modo, "[...] ao trabalhador um poder de barganha e uma liberdade de escolha".

6 A Reforma do Estado no governo de Fernando Henrique Cardoso foi realizada nos preceitos do Consenso de Washington e guiada por Bresser Pereira no Ministério da Administração Federal e Reforma do Estado (MARE). De acordo com Montaño (2010, p. 45), Bresser Pereira, regido por critérios gerenciais, preferia o cidadão-cliente de serviços ao cidadão-usuário de direitos, pois o critério do primeiro seria o melhor atendimento ao cidadão-cliente a um custo menor.

7 O PBF foi criado em 2003 pela MP no 132, convertida na Lei no 10.836 , de 9 de janeiro de 2004 e regulamentado pelo Decreto no 5.209 de 17 de setembro de 2004.

8 A criação do Sistema Único de Assistência Social-SUAS, institucionalizada em 2005, tem relação com a estruturação da política de Assistência Social a partir daLei Orgânica da Assistência Social - LOAS, com a construção de um sistema descentralizado de assistência social que é caracterizada por um sistema públiconão contributivo, descentralizado e participativo com a integração das ações entre os governos federal, estaduais e municipais e de entidades privadas. Propõe o enfoque na proteção social, a partir da configuração de um sistema de atendimento de Proteção Social Básica (por meio dos Centros de Referência da Assistência Social-CRAS) - é neste nível que está localizado o acompanhamento das famílias beneficiárias de programas de transferência de renda, Proteção Social Especial de Média Complexidade (CREAS) e Proteção Social Especial de Alta Complexidade.

9 A Agenda trata dos assuntos ligados aos compromissos que os beneficiários assumem através das condicionalidades e informa sobre o funcionamento do programa e a obrigatoriedade dos municípios em oferecer serviços básicos.

10 Cadastro Único para Programas Sociais do Governo Federal (CadÚnico), 2001.

11 Nesse ínterim, cabe pontuar que entre os anos de 2011 e 2014 (governo de Dilma V. Rousseff, do PT) o Brasil contou com taxas de desocupação próximas de $4,5 \%$, consideradas como um cenário de pleno emprego. No entanto, o número de famílias atendidas pelo PBF nesse período foi, em média, de 13,8 milhões. (De Sordi, 2019, p. 165).

12 Disputa que pode ser notada no Projeto de Lei 286/2009 de Buarque que propõe alterar o nome do PBF para Programa Bolsa Escola. A justificativa segue a argumentação citada no excerto.

13 Vulnerabilidade é um termo que começa a ser amplamente utilizado nos anos de 1990, conforme registra Mariel Deak Serapião (2018, p. 36): "Esta aborda- 
gem entra em cena nos anos 1990 a partir dos estudos sobre risco, desastres e ameaças naturais, passando depois a ser utilizada nos estudos sobre pobreza e privação. Ela entrou na agenda de diversas instituições internacionais - tais como o Departamento para o Desenvolvimento Internacional (DFID), o Instituto de Estudos sobre Desenvolvimento (IDS), Oxfam e PNUD, entre outros - que foram responsáveis pela disseminação dessa agenda através da produção de estudos sobre vulnerabilidade e de uma série de manuais (guidancesheets) que tinham como objetivo propagar o uso desse framework teórico”.

\section{Referências}

ARROYO, Miguel Gonzales. Políticas Educacionais e Desigualdades: à procura de significados. Educação \& Sociedade, Campinas, v. 31, n. 113 p. 1381-1416, out./dez. 2010.

BARBOSA, Ana Luiza Neves de Holanda; CORSEUIL, Carlos Henrique Leite. Bolsa Família, Escolha Ocupacional e Informalidade no Brasil. In: CAMPELLO, Tereza; NERI, Marcelo Côrtes (Org.). Programa Bolsa Família: uma década de inclusão e cidadania. Brasília: Ipea, 2013. P. 327-339.

BASSANI, Elizabete; CALIARI, Rogério; DALVI, Maria Amélia; SIMÕES, Vera; ZANIN, Larissa. Entrevista - Questões para Dermeval Saviani. Pró-Discente: Caderno de Produções Acadêmico-Científicas do Programa de Pós-Graduação em Educação, p. 110-117, Vitória, v. 15, n. 2, ago./dez. 2009.

BAVA, Silvio Caccia (Org.). Programas de Renda Mínima no Brasil: impactos e potencialidades. São Paulo: PÓLIS, 1998.

BEHRING, Elaine Rossetti; BOSCHETTI, Ivanete. Política Social-fundamentos e história. São Paulo: Cortez, Biblioteca Básica de Serviço Social, 2006.

BHATTACHARYA, Tithi. O Que É a Teoria da Reprodução Social? Revista Outubro, n. 32, p. 99-113, 1 semestre de 2019.

BRASIL. Ministério do Desenvolvimento Social e Combate à Fome. Programa Bolsa Família - Agenda da Família. Brasília: 2010.

BUARQUE, Cristovam. A Revolução nas Prioridades: da modernidade técnica à modernidade ética. São Paulo: Paz e Terra, 1994.

BUARQUE, Cristovam. Bolsa Escola, História, Teoria e Utopia. Brasília: Thesaurus/Liber, 2012.

CAMARGO, José Márcio. Pobreza e Garantia de Renda Mínima. Opinião Econômica. Dinheiro. Folha de S. Paulo, 26 dez. de 1991. Acervo Folha. Disponível em: <http://acervo.folha.uol.com.br/resultados/?q=josé+márcio+ camargo $+\&$ site $=$ fsp \&periodo=acervo $\& x=13 \& y=13>$. Consultado em: 29 set. de 2017.

CESTARI, Regina. A LDB e o Contexto Nacional: o papel dos partidos políticos na elaboração dos projetos - 1986 a 1996. 1997. 370 f. Tese (Doutorado em História da Educação) - Universidade Estadual de Campinas, Campinas, 1997.

CIDAMAMORE, Alberto. As Políticas de Produção da Pobreza: construindo enfoques teóricos integrados. In: CATTANI, Antonio David; CIDAMAMORE, Alberto (Org.). Produção da Pobreza e Desigualdade na América Latina. Trad. Ernani Ssó. Porto Alegre: Tomo Editorial/CLACSO, 2007. P. 15-38.

COHN, Amélia. Cartas ao Presidente Lula: Bolsa Família e direitos sociais. Rio de Janeiro: Pensamento Brasileiro, 2012. 
A Educação nos Programas Sociais Brasileiros

CORREIO. Bird: falta de ensino gera pobreza. Correio do Triângulo, n. 175, política, p. 2, 21 set. 1993.

CORREIO. MEC abre inscrições para bolsa-escola. p. A-2. Correio do Triângulo, n. 265, 15 mar. 2001.

DE SORDI, Denise. Reformas nos Programas Sociais brasileiros: solidariedade, pobreza e controle social (1990-2014). 2019. 316 f. Tese (Doutorado) - Programa de Pós-Graduação em História, Universidade Federal de Uberlândia, Uberlândia, 2019

DRAIBE, Sônia. A Política Social no Período FHC e o Sistema de Proteção Social. Tempo Social, Universidade de São Paulo, São Paulo, v. 15, n. 2, p. 63-101, 2003.

GENTILI, Pablo. Neoliberalismo e Educação: manual do usuário. In: SILVA, Tomaz Tadeu; GENTILI, Pablo (Org.). Escola S.A: quem ganha e quem perde no mercado educacional do neoliberalismo. Brasília: CNTE, 1996. P. 9-49.

GENTILI, Pablo. Adeus à Escola Pública: a desordem neoliberal, a violência do mercado e o destino da educação das maiorias. In: GENTILI, Pablo (Org.). Pedagogia da Exclusão: crítica ao neoliberalismo em educação. 19 ed. Petrópolis: Vozes, 2011. P. 228-252.

GOHN, Maria da Glória. Teorias dos Movimentos Sociais - paradigmas clássicos e contemporâneos. 3 ed. (2002). São Paulo: Edições Loyola, 1997.

GOHN, Maria da Glória. Novas Teorias dos Movimentos Sociais. 5 ed. São Paulo: Edições Loyola, 2014.

HILLESHEIM, Jaime; GARCIA, Adir Valdemar. Educação e Trabalho no Brasil: a perspectiva defendida pelo capital para a formação dos trabalhadores. Revista Katálysis, Florianópolis, v. 22, n. 3, p. 479-490, set./dez. 2019.

JUSTO, Carolina Raquel Duarte de Mello. Política de Transferência de Renda e Cidadania no Brasil: implicações político-sociais dos programas municipais de renda mínima a partir do estudo comparativo dos casos de Campinas, Jundiaí, Santo André e Santos (1995-2006). 2007. I Tese. (Doutorado em Ciências Sociais). Universidade Estadual de Campinas, Campinas, SP, 2007.

KAWAUCHI, Mary. O Programa Bolsa Família e Percepções de Não Beneficiários: um estudo sobre o efeito preconceito. 2019. 205 f. Tese (Doutorado em Desenvolvimento, Sociedade e Cooperação Internacional). Universidade de Brasília, Brasília, 2019.

LEHER, Roberto. Um Novo Senhor da Educação? A política educacional do Banco Mundial para a periferia do capitalismo. Outubro, São Paulo, v. 1, n. 3, p. 19-30, 1999.

LIMA, Paulo Gomes; ARANDA, Maria Alice de Miranda; LIMA, Antonio Bosco. Políticas Educacionais, Participação e Gestão Democrática da Escola na Contemporaneidade Brasileira. Revista Ensaio, Belo Horizonte, v. 14, n. 01, p. 51-64, jan./abr. 2012.

MARINS, Mani Tebet. Repertórios Individuais e Estratégias Individuais de Beneficiários do Bolsa Família. Sociologia \& Antropologia, Rio de Janeiro, v. 4, n. 2, p. 553-562, out. 2014.

MAURIEL, Ana Paula Ornellas. Combate à Pobreza e Desenvolvimento Humano: impasses teóricos na construção da política social na atualidade. 2008. 351 f. Tese (Doutorado) - Programa de Pós- Graduação em Ciências Sociais. Universidade Estadual de Campinas, Campinas, 2008. 
MONTAÑO, Carlos. Terceiro Setor e Questão Social: crítica ao padrão emergente de intervenção social. São Paulo: Cortez, 2010.

OLIVEIRA, Francisco de. Política numa Era de Indeterminação: opacidade e reencantamento. In: OLIVEIRA, Francisco de; SALIBA RIZEK, Cibele (Org.). A Era da Indeterminação. São Paulo: Boitempo, 2007. P. 15-45.

OLIVEIRA, Francisco de. O Adeus do Futuro ao País do Futuro: uma biografia breve do Brasil. In: OLIVEIRA, Francisco de. Brasil: uma biografia não autorizada. São Paulo: Boitempo, 2018. P. 27-78.

PETITAT, André. Produção da Escola/ Produção da Sociedade: análise sóciohistórica de alguns momentos decisivos da evolução escolar no ocidente. Porto Alegre: Artes Médicas, 1994.

PINZANI, Alessandro; REGO, Walquiria Leão. Vozes do Bolsa Família: autonomia, dinheiro e cidadania. São Paulo: Editora Unesp, 2014.

ROCHA, Sonia. Transferências de Renda: o fim da pobreza. Rio de Janeiro: Elsevier, 2013.

SAVIANI, Demerval. Escola e Democracia: teorias da educação, curvatura da vara, onze teses sobre educação e política. 32 ed. Campinas: Autores Associados, 1999. (Col. Polêmicas do nosso tempo, vol. 5).

SEN, Amartya. Desenvolvimento como liberdade. São Paulo: Companhia das Letras, 2010.

SENADO FEDERAL. Conferência Internacional Renda Mínima: Discussões e Experiências. 11 e 12 ago. de 1998 Disponível em <http://www.senado.gov.br/ web/senador/esuplicy/frm_rendaminima.htm>. Acesso em: 25 set. 2004.

SERAPIÃO, Mariel Deak. O Bolsa Família no Cotidiano: conexões e desconexões em um território vulnerável. 2018. 165 f. Dissertação (Mestrado em Administração Pública e Governo) - Programa de Pós-Graduação em Administração Pública e Governo, Escola de Administração de Empresas, Fundação Getúlio Vargas, São Paulo, 2018.

SHIROMA, Eneida. Política Educacional. Rio de Janeiro: Editora Dp\&A, 2004.

SILVA, Maria Ozanira da Silva; YAZBEK, Maria Carmelita; DI GIOVANNI, Geraldo. A Política Social Brasileira no Século XXI: a prevalência dos programas de transferência de renda. 7 ed. São Paulo: Cortez, 2014.

SINGER, Paul. Globalização e Desemprego. Diagnóstico e alternativas. 5 ed. São Paulo: Contexto, 2001. P. 119-20.

SOARES, Maria Clara Couto. Banco Mundial: políticas e reformas. In: TOMMASI, Lívia; WARDE, Mirian; HADDAD, Sérgio (Org.). O Banco Mundial e as Políticas Educacionais. São Paulo: Cortez, 1996.

SUPLICY, Eduardo Matarazzo. Renda de Cidadania: a saída é pela porta. São Paulo: Cortez - Fundação Perseu Abramo, 2002.

TELES, Alan; STEIN, Rosa. Programas de Transferência de Renda e Condicionalidades Educacionais: acesso ao direito ou moralização do acesso?. In: YANNOULAS, Silvia Cristina (Org.). Política Educacional e Pobreza: múltiplas abordagens para uma relação multideterminada. Brasília: Liber Livro, 2016. P. $183-213$

TELlES, Vera da Silva. Pobreza e Cidadania. São Paulo: Programa de PósGraduação em Sociologia da FFLCH-USP/Editora 34, 2013.

VALENTE, Ana Lúcia. O Programa Nacional de Bolsa Escola e as Ações Afirmativas no Campo Educacional. Revista Brasileira de Educação, n. 24, p. 165-182, set./out./nov. 2003.

Educação \& Realidade, Porto Alegre, v. 46, n. 3, e106751, 2021. 
VICENTE, João Pedro Aparecido; GONÇALVES NETO, Wenceslau. Institucionalização do Toyotismo: aliança entre academia e mercado. RDP, Uberaba, v. 18, n. 39, p. 432-450, jul./dez. 2018.

WORLD BANK. Brazil: an assessment of the Bolsa Escola programs. Washington: The World Bank, Human Development Sector Management Unit, Brazil Country Management Unit, Latin America and the Caribbean Regional Office, 2002.

Denise De Sordi é historiadora. Doutora em História Social pelo PPGHI/ UFU. Pesquisadora do GPEPS/CNPq/UFU. Investigadora associada ao OCVT/FCSH/UNL.

ORCID: https://orcid.org/0000-0003-0536-2863

E-mail: denisends@me.com

Wenceslau Gonçalves Neto é Doutor em História pela Universidade de São Paulo (USP). Professor dos Programas de Pós-Graduação em Educação da Universidade de Uberaba (UNIUBE) e Universidade Federal de Uberlândia (UFU). Bolsista Produtividade em Pesquisa do CNPq (Conselho Nacional de Desenvolvimento Científico e Tecnológico) e do Programa Pesquisador Mineiro da FAPEMIG (Fundação de Amparo à Pesquisa do Estado de Minas Gerais).

ORCID: http://orcid.org/0000-0002-4374-0311

E-mail:wgneto55@gmail.com

Editor-Responsável: Luís Armando Gandin

Este é um artigo de acesso aberto distribuído sob os termos de uma Licença Creative Commons Atribuição 4.0 Internacional. Disponível em: <http:// creativecommons.org/licenses/by/4.0>. 